\title{
Successful use of a right ventricular assist device
}

\author{
PHILIP BELCHER, BRIAN GLENVILLE, LEN COOPER \\ From the Brompton Hospital, London
}

SUMMARY Right ventricular failure caused by myocardial infarction may be refractory to treatment designed to support the systemic ventricle. A new type of right ventricular assist device driven by an impeller pump was successfully used for 79 hours after emergency revascularisation after right coronary occlusion. Despite renal failure requiring haemofiltration the patient has now fully recovered.

Right ventricular failure due to infarction on the diaphragmatic surface is characterised by hypotension, neck vein engorgement, and heart block. ${ }^{1}$ The addition of clinically significant infarction of the left ventricular free wall and septum may contraindicate any effort to increase the right ventricular preload and may also diminish the effectiveness of pulmonary vasodilators which are the mainstay of treatment when right ventricular failure is caused by pulmonary hypertension. Left ventricular function is also embarrassed by inadequate preload caused by insufficient blood crossing the pulmonary vasculature; if this cannot be improved by standard inotropic and vasodilator methods right ventricular assistance is required to maintain systemic perfusion. Right ventricular bypass should also relieve overdistension of the ventricle thus allowing recovery by promoting coronary blood flow to viable muscle.

We describe the successful use of a simple, cheap, and adaptable right ventricular assist device; it was used to support the failing right ventricle when inotropes, vasodilators, and an intra-aortic balloon pump had failed to maintain adequate circulation and prevent progressive acidosis. There are reports of three survivors in whom the combination of an intra-aortic balloon and a right ventricular assist device was used; but none of them had renal failure. $^{2-4}$ In the present case renal failure was treated by the addition of a haemofiltration circuit.

\section{Case report}

A 63 year old previously well woman with a history of severe unstable angina was transferred for cardi-

Requests for reprints to Mr Philip Belcher, FRCS, Brompton Hospital, Fulham Road, London SW36HP. ological assessment to London. Cardiac catheterisation showed moderate left ventricular function, occlusion of the anterior descending coronary artery, and $95 \%$ stenosis of a large marginal coronary artery. The right coronary had an ostial stenosis and six hours after catheterisation she suffered a large inferior infarct. Despite administration of vasodilators she continued to have rest pain. She was transferred to the Brompton Hospital three days later. On admission blood pressure was $90 \mathrm{~mm} \mathrm{Hg}$ and jugular venous pressure was raised $8 \mathrm{~cm}$. Chest $x$ ray showed diversion of venous blood to the upper lobe; the electrocardiogram showed sinus rhythm and a large inferior infarct. Pain continued and emergency revascularisation was therefore carried out. After sternotomy the blood pressure was $80-90 \mathrm{~mm} \mathrm{Hg}$ and central venous pressure was $20 \mathrm{~mm} \mathrm{Hg}$; rhythm was junctional. The right atrium was tense and immobile. Both ventricles were infarcted on their diaphragmatic surfaces. The remainder of the left ventricular free wall moved well but the right ventricle, apart from the outflow tract, was dilated and immobile but not obviously infarcted. The posterior descending, marginal, and anterior descending (internal mammary artery graft) arteries were grafted. She tolerated the procedure well and cardiopulmonary bypass was discontinued without difficulty. She was in slow junctional rhythm with blood pressure $90 \mathrm{~mm} \mathrm{Hg}$ and central venous pressure $18-20 \mathrm{~mm} \mathrm{Hg}$ on isoprenaline $0.03 \mu \mathrm{g} / \mathrm{kg} / \mathrm{min}$ with glyceryl trinitrate infusion.

During the first six hours she was stable, but then blood pressure fell and urine output declined (fig 1). She required pacing and an increased dose of inotropes (dopamine, adrenaline, and isoprenaline) (fig 2). Over the next 12 hours central venous pressure rose from 22 to $30 \mathrm{~mm} \mathrm{Hg}$ and acidosis increased despite repeated correction with bicar- 


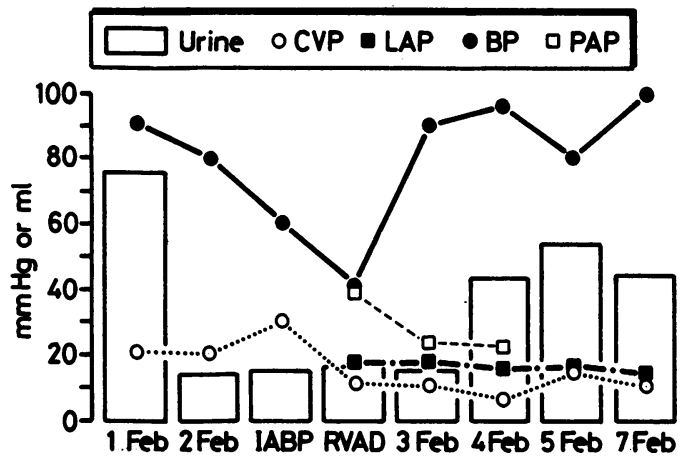

Fig 1 Urine output, blood pressure, and pressures measured at cardiac catheterisation in a patient with right ventricular failure who was treated with a right ventricular assist device. $I A B P$, after insertion of intra-aortic balloon pump; $R V A D$, after insertion of right ventricular assist device; $C V P$, central venous pressure ( $\mathrm{mm} \mathrm{Hg}$ ); LAP, left atrial pressure $(\mathrm{mm} \mathrm{Hg}) ; \mathrm{PAP}$, pulmonary artery pressure $(\mathrm{mm} \mathrm{Hg})$.

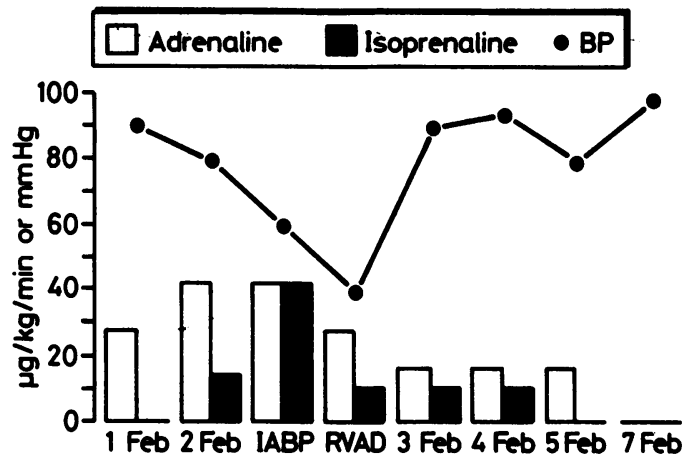

Fig 2 Blood pressure and doses of adrenaline and isoprenaline used to treat a patient with right ventricular failure. See legend to fig 1 for abbreviations.

bonate and insertion of an intra-aortic balloon pump. She was therefore returned to the operating theatre. External findings were similar to before. The pulmonary artery and superior vena cava were cannulated and connected percutaneously through the right hypochondrium to the right ventricular assist device and the chest was closed. The right ventricle could thus be bypassed variably. The assist device was made up of a Centrimed impeller pump without reservoir in a closed circuit. Flow was adjusted to optimise left ventricular performance: at $21 / \mathrm{min}$ left ventricular function improved dramatically with a systolic pressure of $100 \mathrm{~mm} \mathrm{Hg}$ and left atrial pressure of $16 \mathrm{~mm} \mathrm{Hg}$; however, when the flow rate was further increased the left atrial pressure rose considerably and systemic blood pressure fell rapidly. Flows were therefore kept at $1-21 / \mathrm{min}$ for the next 79 hours while (fig 1 ) the pulmonary artery pressure steadily declined to normal $(30 / 15 \mathrm{~mm} \mathrm{Hg})$ which was maintained when the assist device was stopped for periods of up to 60 seconds. Improvement was noticeable within 24 hours of insertion of the device and inotropic requirements declined considerably (fig 2 ). Partial heparinisation was maintained. The assist device was removed without difficulty 79 hours after operation. The right ventricle, apart from its diaphragmatic surface, was then seen to be beating well. The balloon pump was removed two days later.

After insertion of the assist device, renal failure (creatinine clearance $2.4 \mathrm{ml} / \mathrm{min}$ ) was treated by haemofiltration with a Diafilter-20 (Amicon, Danvers, MA 01923, USA) connected in parallel with the assist device circuit. Urine output (fig 1) improved to over $30 \mathrm{ml} / \mathrm{h}$ with creatinine clearance still $2.4 \mathrm{ml} / \mathrm{min}$. Urine osmolality rose from $308 \mathrm{mOsm} / 1$ to $387 \mathrm{mOsm} / 1$ and creatinine clearance to $16 \mathrm{ml} / \mathrm{min}$ by the twelfth day. Creatinine clearance was $48 \mathrm{ml} / \mathrm{min}$ by the 25 th day and $95 \mathrm{ml} / \mathrm{min}$ on the 32nd postoperative day; creatinine clearance had peaked at $590 \mu \mathrm{mol} / 1$.

She was extubated on the 35th day after cardiac output had been measured by thermodilution. Heart rate was 120 beats/min, central venous pressure was $15 \mathrm{~mm} \mathrm{Hg}$, right ventricular pressure $39 / 8 \mathrm{~mm} \mathrm{Hg}$, and pulmonary artery pressure $34 / 20$ (mean 25) $\mathrm{mm} \mathrm{Hg}$. Cardiac output (mean of three measurements) was $4.91 / \mathrm{min}$, systemic vascular resistance 11.4 units, pulmonary vascular resistance 1.84 units, and stroke volume $40 \mathrm{ml}$. These data indicate a highly satisfactory recovery. Echocardiography was unhelpful.

Outpatient review at five months resulted in referral for femoral artery reconstruction which was successfully performed at 10 months. Echocardiography at five months showed a normal sized right ventricular cavity and slight left ventricular enlargement with normal function.

\section{Discussion}

Right ventricular failure is often a secondary effect of left ventricular failure or other causes of pulmonary hypertension. In the case described, although the left ventricular infarct adversely affected pulmonary vascular resistance, infarction of the right ventricular diaphragmatic surface was the prime cause of right ventricular failure. Treatment was designed initially to off load the right ventricle pharmacologically and to optimise left ventricular performance. The lack of effect of balloon counterpulsation on right ventricular function confirmed the visual impression at operation that right ventricular pump failure was the main problem. 
What are the options when a patient has seemingly intractable right ventricular failure? Increasing the preload on the right ventricle even further and off loading the systemic circulation can be successful; four of six patients with near normal left ventricular function survived this treatment. ${ }^{1}$ In the present case, the right atrium was already overloaded and left ventricular function was obviously depressed; further volume loading was ineffective. Fear of terminal right ventricular overdistension prompted us to use an assist device.

In sheep and goat preparations pulmonary artery balloon counterpulsation is reported to provide some assistance to forward flow in pulmonary hypertension. ${ }^{5}$ However, when the balloon is placed in a side arm attached to the pulmonary artery it will directly promote forward flow and this method has been used clinically and experimentally with moderate benefit. ${ }^{67}$ This is slight compared with passive flow and markedly inferior to that achieved with a right ventricular pump assist device. ${ }^{8}$

Long term complete bypass requires full heparinisation and a membrane oxygenator, and a perfusionist must be in continuous attendance. Problems are mainly caused by progressive depletion of clotting factors and destruction of red cells and platelets. Isovolumic left ventricular contraction enhances right ventricular pump function and if the left ventricle is completely decompressed, right ventricular function declines. ${ }^{9}$ Roller pumps may produce tubing splitting and spallation of particles within the circulation. Some of these problems occurred with extracorporeal membrane oxygenation but were overcome by centrifugal or impeller pumps with no or minimal heparinisation. Such measures should reduce the risk of bleeding, which can cause considerable mortality. ${ }^{10}$

In our case the right ventricle was unable to pump sufficient blood for the damaged left ventricle to perform properly. This necessitated the use of a right ventricular assist device with the patient's lungs for oxygenation. Flow rates were adjusted to "balance" the respective ventricular failures. The technique used a closed circuit and avoided the need for an oxygenator and reservoir, thereby reducing the supervision required and the possibility of accidents. We used a type of impeller pump that had not previously been used in a right ventricular assist device. Because of this low levels of heparinisation were adequate. No clots were seen when the device was removed. The system was easily adapted to the addition of a haemofiltration circuit. Disposable equipment cost approximately $£ 380$.

There is a moderately large experience in the United States with sac type ventricular assist devices, but they are expensive and scarce in the
United Kingdom. Both experimental work in animals and limited clinical data suggest that pneumatic assist devices are hard to adjust to provide the low flows required. Higher flows resulted in left ventricular failure in this patient whose infarct involved the diaphragmatic wall of the left ventricle.

It is generally agreed that the device should be inserted if adequate catecholamine support and balloon counterpulsation are ineffective after a trial period of 60-120 minutes. ${ }^{1112}$ However, when left atrial pressure is low, aortic balloon counterpulsation is unlikely to improve right ventricular performance and this step seems unnecessary unless left ventricular failure is unmasked by the right ventricular assist device. The timing of removal is somewhat variable. As a general guideline, haemodynamic function will either show a recovery within four days or multisystem failure will have supervened; the prognosis is particularly poor when there is apical necrosis. ${ }^{13}$

Management of renal failure in this case was greatly helped by insertion of a haemofilter into the assist device circuit. This allowed removal of water and electrolytes and partial recovery of renal function to a level at which dialysis was no longer required.

This technique may have implications for the long term survival of patients in whom right ventricular failure follows pulmonary embolectomy or closure of postinfarction ventricular defect.

We thank Mr J C R Lincoln FRCS for his encouragement and $\mathrm{Mr} \mathrm{T}$ McCarthy for help with the illustrations.

\section{References}

1 Cohn JN, Guiha NH, Broder MI, Limas CJ. Right ventricular infarction. Clinical and hemodynamic features. Am J Cardiol 1974;33:209-14.

2 Pennington DG, Merjavy JP, Swatz MT, et al. The importance of biventricular failure in patients with postoperative cardiogenic shock. Ann Thorac Surg 1985;39:16-25.

3 Myers JL, Parr GVS, Pae WE, Waldhausen JA, Pierce WS. The role of the ventricular assist pump for postcardiotomy cardiogenic shock: a four and one-half year experience. Proceedings of the third meeting of the ISAO. Artif Organs 1981;5(suppl):244-51.

4 Pennington DG, Merjavy JP, Codd JC, Swartz MT, Willman VL. Temporary mechanical support of patients with profound ventricular failure. In: Unger F, ed. Assisted circulation. Vol. 2. Berlin: SpringerVerlag: 85-99.

5 Kralios AC, Zwart HHJ, Moulopoulos SD, Collan R, Kwan-Gett CS, Kollf WJ. Intrapulmonary artery balloon pumping. Assistance of the right ventricle. $J$ Thorac Cardiovasc Surg 1970;60:215-32. 
6 Jett GK, Siwek LG, Picone AL, Applebaum RE, Jones M, Austen WG. Pulmonary artery balloon counterpulsation for right ventricular failure. An experimental evaluation. J Thorac Cardiovasc Surg 1983; 86:364-72.

7 Miller DC, Moreno-Cabral RJ, Stinson EB, Shinn JA, Shumway NE. Pulmonary artery balloon countetpulsation for acute right ventricular failure. $J$ Thorac Cardiovasc Surg 1980;80:760-3.

8 Gaines WJ, Pierce WS, Prophet GA, Holtzman K. Pulmonary circulatory support. A quantitative comparison of four methods. $J$ Thorac Cardiovasc Surg 1984;88:958-64.

9 Miyamoto AT, Tanaka S, Matloff JM. Right ventricular function during left heart bypass. $J$ Thorac Cardiovasc Surg 1983;85:49-53.

10 Pennington DG, Merjavy JP, Codd JE, Swartz MC,
Miller LL, Williams GA. Extracorporeal membrane oxygenation for patients with cardiogenic shock. Circulation 1984;70(suppl I):130-7.

11 Bernhard WF, Schoen FJ, Poirier V, Carr J. A temporary ventricular assist device for patients exhibiting intractable postcardiotomy shock. In: Unger F, ed. Assisted circulation. Vol. 2. Berlin: Springer-Verlag: 49-69.

12 Richenbacher WE, Wisman CB, Rosenberg G, Donachy JH, Landis DL, Pierce WS. Ventricular assistance: clinical experience at the Pennsylvania State University. In: Unger F, ed. Assisted circulation. Vol. 2. Berlin: Springer-Verlag: 70-84.

13 Bernhard WF, Carr JC, Clay W, et al. Clinical and laboratory investigations related to temporary and permanent ventricular bypass. Heart Transplantation 1983;3:16-25. 